\title{
Fragmentation of the large subunit ribosomal RNA gene in oyster mitochondrial genomes
}

\author{
Coren A Milbury ${ }^{1,3^{*}}$, Jung C Lee ${ }^{2}$, Jamie J Cannone ${ }^{2}$, Patrick M Gaffney ${ }^{1}$, Robin R Gutell ${ }^{2}$
}

\begin{abstract}
Background: Discontinuous genes have been observed in bacteria, archaea, and eukaryotic nuclei, mitochondria and chloroplasts. Gene discontinuity occurs in multiple forms: the two most frequent forms result from introns that are spliced out of the RNA and the resulting exons are spliced together to form a single transcript, and fragmented gene transcripts that are not covalently attached post-transcriptionally. Within the past few years, fragmented ribosomal RNA (rRNA) genes have been discovered in bilateral metazoan mitochondria, all within a group of related oysters.

Results: In this study, we have characterized this fragmentation with comparative analysis and experimentation. We present secondary structures, modeled using comparative sequence analysis of the discontinuous mitochondrial large subunit rRNA genes of the cupped oysters C. virginica, C. gigas, and C. hongkongensis.

Comparative structure models for the large subunit rRNA in each of the three oyster species are generally similar to those for other bilateral metazoans. We also used RT-PCR and analyzed ESTs to determine if the two fragmented LSU rRNAs are spliced together. The two segments are transcribed separately, and not spliced together although they still form functional rRNAs and ribosomes.

Conclusions: Although many examples of discontinuous ribosomal genes have been documented in bacteria and archaea, as well as the nuclei, chloroplasts, and mitochondria of eukaryotes, oysters are some of the first characterized examples of fragmented bilateral animal mitochondrial rRNA genes. The secondary structures of the oyster LSU rRNA fragments have been predicted on the basis of previous comparative metazoan mitochondrial LSU rRNA structure models.
\end{abstract}

\section{Background}

The translation of mRNA into functional proteins occurs within the two subunits of the ribosome. These subunits are typically $30 \mathrm{~S}$ and $50 \mathrm{~S}$ (to form the $70 \mathrm{~S}$ ribosome) in prokaryotes and chloroplasts, $40 \mathrm{~S}$ and $60 \mathrm{~S}$ (to form the $80 \mathrm{~S}$ ribosome) in nuclear encoded eukaryotic ribosomes, and subunit sizes vary considerably in mitochondria.

The small ribosomal subunit (SSU) typically contains a single RNA and exhibits a range of sizes; ribosomal RNA (rRNA) are $16 \mathrm{~S}$ in prokaryotes and chloroplasts [1], 18S in the eukaryotic nuclear genome [1], and varies from 9S [2] to over $18 \mathrm{~S}$ in mitochondrial genomes [3]. The RNA in the small ribosomal subunit (30S or 40S) is

\footnotetext{
* Correspondence: coren_milbury@dfci.harvard.edu

'College of Earth, Ocean, and Environment, University of Delaware, Lewes, DE, USA

Full list of author information is available at the end of the article
}

also called 16S-like rRNA and more typically SSU rRNA. The large ribosomal subunit (LSU) usually contains two or three primary RNAs. Prokaryotic and chloroplast LSUs usually possess a 23S rRNA [1], eukaryotic nuclear genomes contain 25-28S and 5.8S rRNAs [1], and in mitochondria, rRNAs range from $12 \mathrm{~S}$ to $>26 \mathrm{~S}$ $[2,4]$. This RNA in the large ribosomal subunit (50S or $60 \mathrm{~S}$ ) is also called 23S-like rRNA and more typically LSU rRNA. The majority of the mitochondrial ribosomes, including animals, do not contain a 5S rRNA in their LSU; the exceptions are plants [5], protists including some red, green, and brown algae [6-15], and more recently an amoeboid protist, Acanthamoeba castellanii [16] that contain an RNA with the major characteristics of $5 \mathrm{~S}$ rRNAs. The functional ribosome with the $30 \mathrm{~S} / 40 \mathrm{~S}$ and 50S/60S subunits contain at least 50 ribosomal proteins (rProteins) [1]. Although phylogenetic variation in size, sequence, and structure of rRNAs is extensive [17], 
specific regions of the rRNA are conserved in all known organisms. Several of the conserved regions of the SSU and LSU rRNA assemble to form the catalytic core within the center of the ribosome [18].

Typically, 5S, $16 \mathrm{~S}$ and $16 \mathrm{~S}$-like, and $23 \mathrm{~S}$ and 23S-like rRNAs are each encoded from a continuous rRNA gene; however, the rRNA genes infrequently have non-rRNA nucleotide sequences inserted. The two primary types of interrupted rRNA genes are the result of: 1) introns and 2) fragmentation. Introns, the nucleotides within the rRNA gene that do not code for rRNA, are removed during transcript processing, followed by exon splicing or re-ligating, the parts of the rRNA gene that codes for the rRNA [19]. At least 3000 introns have been identified in rRNA $[17,20]$. Discontinuous and fragmented rRNAs can be encoded by at least two noncontiguous regions of the genome that when combined code for a full length rRNA. However, unlike introns, the fragments of the rRNA are not covalently reconnected. Thus, the rRNA in the ribosome is split into at least two fragments.

While the majority of the introns in rRNA occur within highly conserved regions of the rRNA gene, fragmentation occurs in regions of high variability $[17,20]$. In three dimensional space the introns occur on the interface side of the $30 \mathrm{~S}$ and $50 \mathrm{~S}$ ribosomal subunits that have a high percentage of very conserved nucleotides while the regions with large insertions and deletions generally occur on the back side of each of the two subunits where the majority of the large insertions occur in organisms that span the entire tree of life [20].

Two modes of gene organization have been observed for the discontinuous rRNA genes. The first maintains the order of the rRNA sequence in the rRNA gene and the intervening nucleotides in the gene are removed after they are transcribed. The regions that are excised are called internal transcribed spacers (ITS) in eukaryotes, and intervening sequences (IVS) in prokaryotes. Although most rRNAs are coded by a contiguous gene, many examples of discontinuous coding within the rRNA have been documented. Within some closely related bacteria of the same genus, one species (or strain) may have an insertion and discontinuous coding at a specific location in the rRNA structure (e.g. Campylobacter jejuni [21]) while another species in the same genus does not have an insertion at the same location in the LSU rRNA and has a single continuous 23S rRNA (e.g. Campylobacter coli [22]). Many other examples of discontinuity that maintains the genetic order of the functional rRNA have been identified in eukaryotes and have been reviewed in Gray and Schnare [23,24].

The second type of discontinuous genes occurs less frequently. Here the rRNA-encoding regions are separated by tRNA- or protein-encoding genes rather than introns. In a few cases, the functional order of rRNA fragments has been rearranged in addition to the insertion of non-rRNA gene fragments. For example, gene fragmentation and rearrangement have been observed in the SSU and/or LSU rRNAs in the mitochondrial genomes of the fungus Haloraphidium curvatum [25], as well as ciliates Tetrahymena pyriformis and Paramecium aurelia [26,27]. Extensive ribosomal fragmentation and rearrangement have also been observed in rRNA genes in the mitochondrial genomes of chlorophycean and prasionophycean green algae Chlamydomonas reinhardtii [28], C. eugametos [29], and inferred in other Chlamydomonas species [30] and other green algae mitochondria based on isolation of rRNA fragments [31], such as Chlorogonium elongatum [32] and Pedinomonas minor [7]. The most extensive fragment rearrangement of the rRNA gene occurs in protistan apicomplexans (such as Theileria parva [33] and Plasmodium falciparum [34-36]) and dinoflagellates [37-39] (such as Oxyrrhis marina [40] and Alexandrium catenella [41]).

While fragmented and rearranged ribosomal RNA genes have been observed in bacteria and eukaryotic nuclear, chloroplast and mitochondrial RNA genes, the first discontinuous ribosomal RNA gene in a bilateral metazoan mitochondrial genome was reported in 2005 Crassostrea virginica [1] and subsequently found in two other strains of Crassostrea, C. gigas [42] and C. hongkongensis $[43,44]$ The first discontinuous rRNA gene in a non-bilateral metazoan Placozoan, Trichoplax adhaerens was reported in 2006 [45] followed by the identification of three additional discontinuous rRNAs in the same Placozoan phylogenetic group [46].

The characterization and modeling of the secondary structures of the fragmented LSU rRNA genes is essential to determine its location in the rRNA's higher-order structure, gain an understanding of how these gene fragments associate to form functional rRNAs and ribosomes, and relate the conserved and variable regions with the high resolution crystal structures and the functional components of the ribosomal RNA in protein synthesis. This fragmentation is also important as it could help us understand the rearrangements within an organism's genome.

Using reverse-transcriptase polymerase chain reaction (RT-PCR), and analysis of EST sequences, we demonstrate that the two LSU rRNA fragments predicted with comparative analysis are not spliced together post-transcriptionally in Crassostrea virginica. The secondary structure of these fragmented ribosomal LSU RNA genes in the cupped oysters Crassostrea virginica, $C$. gigas, and $C$. hongkongensis, have been modeled and are described herein. 


\section{Results and discussion}

\section{RT-PCR analysis of Crassostrea virginica}

Ribonucleic acid (RNA) and deoxyribonucleic acid (DNA) were individually extracted from adductor muscle of the oyster Crassostrea virginica. Reverse-transcriptase (RT)-PCR was performed on the $C$. virginica RNA to generate complementary DNA (cDNA). PCR amplification was performed to amplify portions of the 5 ' half and 3' halves of the LSU rRNA genes from both the DNA and cDNA templates. The anticipated amplicons were produced for both portions of the LSU rRNA (233 bp amplicon and 434 bp amplicon) from both the DNA and the cDNA template (Table 1, Figure 1). However, a $\sim 773$ bp region could not be amplified from the cDNA template using primers located in the 5' and 3' portions of the LSU rRNA gene. Amplification was simultaneously performed in the bay scallop Argopecten irradians, a related mollusk with a full length, contiguous LSU gene [47] with regions of conservation where primers were situated (GenBank: DQ665851). As apparent in Figure 1, the $748 \mathrm{bp}$ region of the LSU rRNA gene was successfully amplified in the genomic DNA and cDNA of Arogopecten irradians; this region could not be amplified in Crassostrea virginica genomic DNA or cDNA. The lack of amplification with the third primer set indicates that $C$. virginica mRNA is not post-transcriptionally modified by splicing to generate a fulllength LSU rRNA, nor is there a functional full-length LSU gene elsewhere in the genomic DNA of $C$. virginica.

\section{Secondary Structure Analysis of the Large Subunit rRNA}

The LSU rRNA gene in each of the three respective cupped oyster mitochondrial genomes is split into two fragments separated by a large number of nucleotides (9958-9960 nts in C. virginica, 6662-6663 nts in $C$. gigas, and 11999 nts in C. hongkongensis); this phenomenon has not been previously characterized in any bilateral metazoan mitochondrial genome.

No introns were identified by screening the non-coding regions of the $C$. virginica mitochondrial genome using Rfam [48] and tools and data available at the Comparative RNA Website (CRW) [17]. Additional evidence that the two fragments of the LSU rRNA are not ligated into a single rRNA molecule are: (1) several complete protein genes (needed by the mitochondria for its function) are located between the two segments of the gene and have been observed in other mitochondrial genomes; (2) fragmentation in the oyster LSU rRNA gene occurs in highly variable region of the RNA, while introns, and the ligation of gene fragments, always occur (with a few minor exceptions) in highly conserved regions of the rRNA) [20]; and (3) the existence of expressed sequence tags (ESTs), not determined experimentally herein, revealed that the two fragments of the LSU rRNA were not ligated into a single RNA. We used these ESTs to infer the transcripts and gene boundaries. The 5' fragment of the $C$. virginica LSU rRNA is inferred to extend from the nucleotide immediately downstream from $\operatorname{trn} D$ (nt 8250, which is the extreme 5 ' position observed in the transcript data), to nucleotide position 8997 , the site of polyadenylation in the majority of transcripts. The 3' fragment of the LSU rRNA gene in $C$. virginica is located from nt 1712 to nt 2430. The 5 ' boundary of this segment is based on two observations from transcript sequences: 1) nt 1712 is the $5^{\prime}$ most position in ESTs matching the 3' portion of the LSU rRNA gene, and 2) nt 1711 is the polyadenylation site for transcripts containing the upstream cytochrome oxidase subunit $1(\operatorname{cox} 1)$ gene. The right boundary is inferred from the observation that transcripts containing the 3' portion of the LSU rRNA gene are polyadenylated after position 2430. In C. virginica [GenBank: AY905542], eleven tRNA genes, and nine protein coding genes separate the 5' and 3' halves of the LSU rRNA gene [42].

In C. gigas [GenBank: AF177226], the inferred location of $5^{\prime}$ fragment of the LSU rRNA gene is between nucleotides 5103 and 5703. Though we can not rule out overlapping gene-boundaries, the inferred start boundary of this fragment is at the first nucleotide following trnQ; nt 5117 represents the 5'-most position found in

Table 1 Primers used to amplify specific regions of the LSU rRNA gene from oyster (Crassostrea virginica) genomic DNA and cDNA template (* primers are from [42])

\begin{tabular}{|c|c|c|c|c|}
\hline Region & Primer & $5^{\prime}$ to $3^{\prime}$ oligonucleotide sequence & Product length & Annealing temperature \\
\hline \multirow[t]{2}{*}{$5^{\prime}$ portion } & $\mathrm{mt} 168-\mathrm{F}^{*}$ & GGATTCTGTTTGTCCGCAGCATT & $233 \mathrm{bp}$ & $50^{\circ} \mathrm{C}$ \\
\hline & $m t 169-R^{*}$ & CACCATATAGCTATCTITAGTTGA & & \\
\hline \multirow[t]{2}{*}{ 3' portion } & $m t 89-F^{*}$ & CAGTACCTGCCCAGTGCGACAA & $494 \mathrm{bp}$ & $58^{\circ} \mathrm{C}$ \\
\hline & $16 \mathrm{SBR} *$ & CCGGTCTGAACTCAGATCACGT & & \\
\hline \multirow[t]{2}{*}{ full LSU rRNA } & dCV-Ai-LSU-f & CTTWWGCAKMATGGCYTTWTGAG & $\sim 773 \mathrm{bp}$ in $\mathrm{CV}_{\mathrm{V}}$ & $55^{\circ} \mathrm{C}$ \\
\hline & $d C V-A i-L S U-r$ & CACGGGGTCTTCTTGTCTWWCTTT & $748 \mathrm{bp}$ in $\mathrm{Ai}$ & \\
\hline
\end{tabular}

The final set of primers was used to amplify scallop (Argopecten irradians) genomic DNA and cDNA, and would amplify in C. virginica cDNA if the fragments were spliced post-transcriptionally. 


\section{A. Crassostrea virginica}

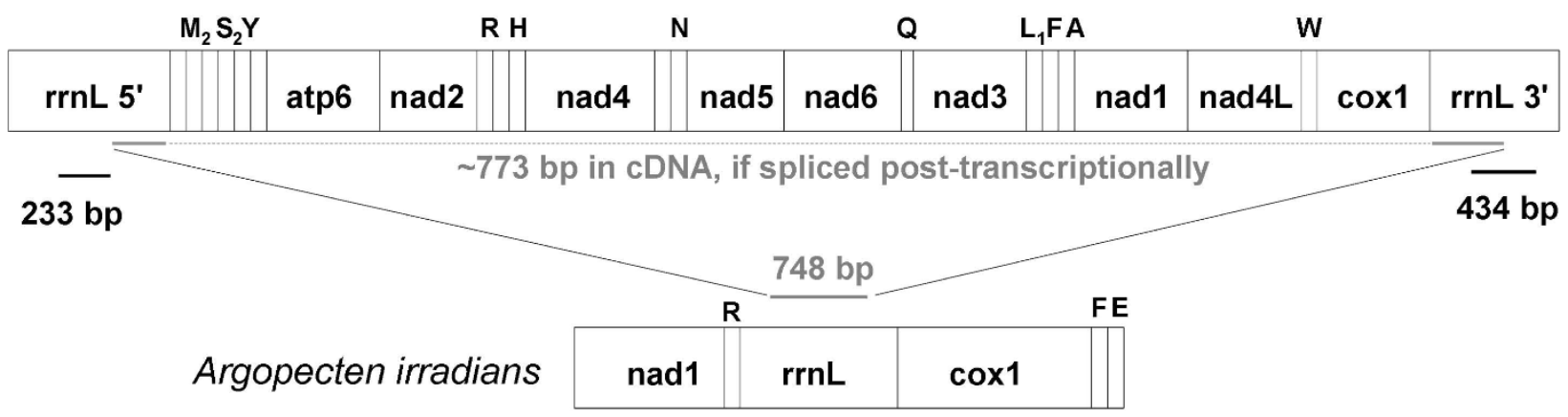

B.

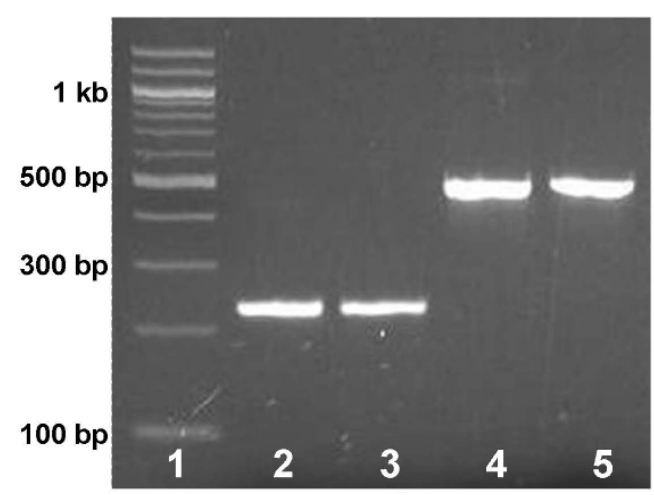

C.

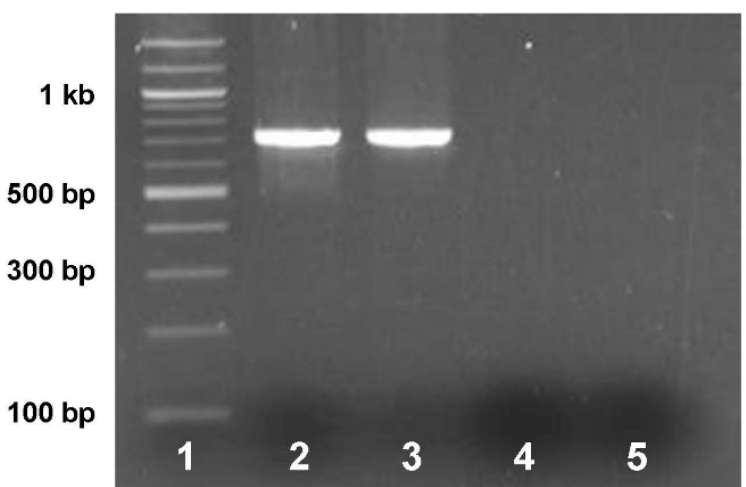

Figure 1 Amplification of mtDNA and cDNA LSU rRNA gene regions in Crassostrea virginica. Diagram A presents the amplicon locations in the $C$. virginica and A. irradians mtDNA genome. Gel image B contains a 233 bp region of the 5'-half LSU amplified from the C. virginica genomic DNA preparation (lane 2) and cDNA preparation (lane 3), as well as a 494 bp region of the 3'-half LSU amplified from the C. virginica genomic DNA preparation (lane 4) and cDNA preparation (lane 5); lane $1=100$ bp ladder. Gel image C: a 748 bp product (starting in the 5' half and ending in the 3' half) amplified from a continuous LSU template in Argopecten irradians genomic DNA (lane 2) and cDNA (lane 3), but was not amplified from C. virginica genomic DNA (lane 4) or CDNA (lane 5).

transcripts containing the LSU rRNA 5' section. The right boundary of this fragment is inferred by transcript polyadenylation at nt $5703 / 5704$. The 3 ' fragment of the LSU rRNA gene is located between nucleotides 17265 and 17977 (slightly different from that annotated in [GenBank: AF177226 (17116..18224)]). The left boundary is based on the observation that cox 1 transcripts in C. gigas extend to nt 17264 , their polyadenylation site; the right boundary represents the polyadenylation site in transcripts containing the 3' portion of the LSU rRNA gene. Twelve tRNA genes, one SSU rRNA gene, nine protein coding genes, and the major non-coding region separate the 5' and 3' halves of the LSU rRNA gene [42].

In the $C$. hongkongensis mitochondrial genome by J. Ren and colleagues [44] [GenBank: EU672834], the 5' fragment of the LSU rRNA gene is located between nucleotides 7780 and 8384 . The boundary of this fragment begins just downstream of $\operatorname{trn} Q$. The mtDNA sequence by $\mathrm{Yu}$ et al. [43] [GenBank: EU266073] is incomplete and does not contain the C. hongkongensis 5' fragment of the LSU rRNA gene sequence. The 3' fragment of the LSU rRNA gene is located between nucleotides 1761 and 2472 [GenBank: EU672834] according to Ren et al. [44], and similarly located at nucleotides 1764-2475 [GenBank: EU266073] by Yu et al. [43]; the two sequences [GenBank: EU672834 and EU266073] are $100 \%$ identical and $712 \mathrm{bp}$ in length. Thirteen tRNA genes, one SSU rRNA gene, nine protein coding genes, and the major non-coding region separate the $5^{\prime}$ and $3^{\prime}$ halves of the LSU rRNA gene [44].

The 5' and 3' halves of the fragmented oyster LSU rRNA contain predicted secondary structural elements that are present in organisms spanning the entire tree of life [17,49-51], features characteristic of bilateral animal mitochondrial LSU rRNAs and features specific to molluscan LSU rRNA. Figures 2, 3, and 4 present the LSU 


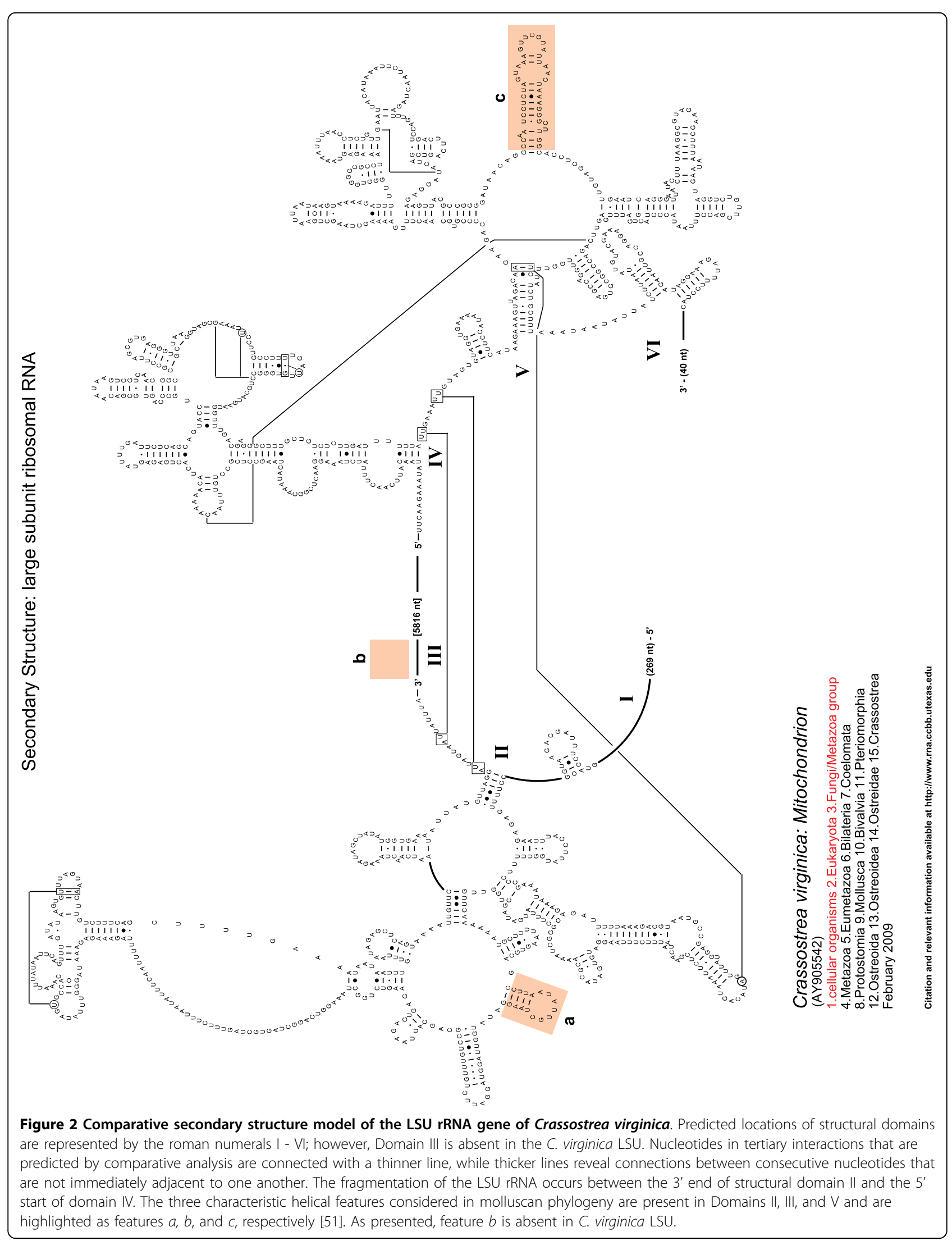




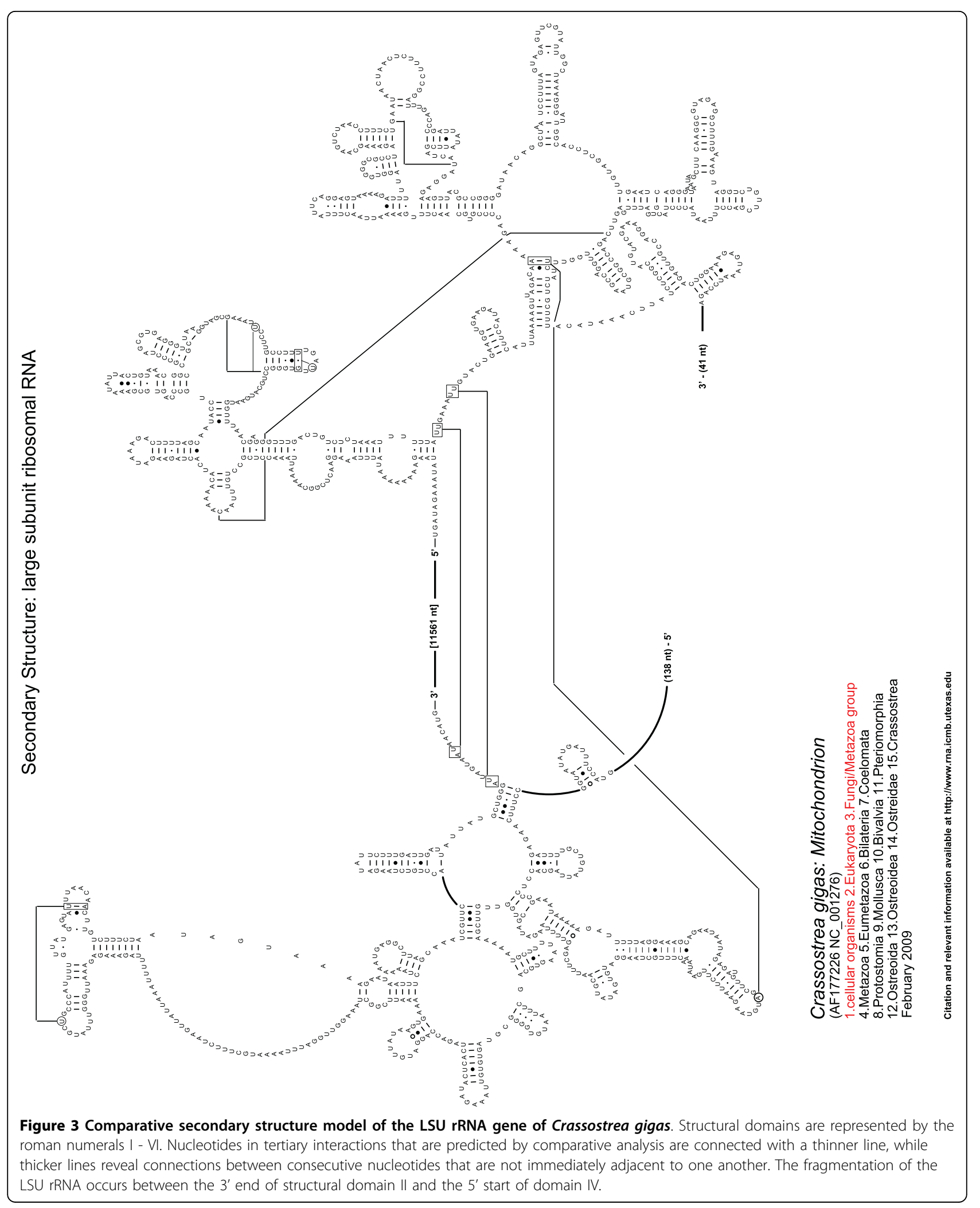




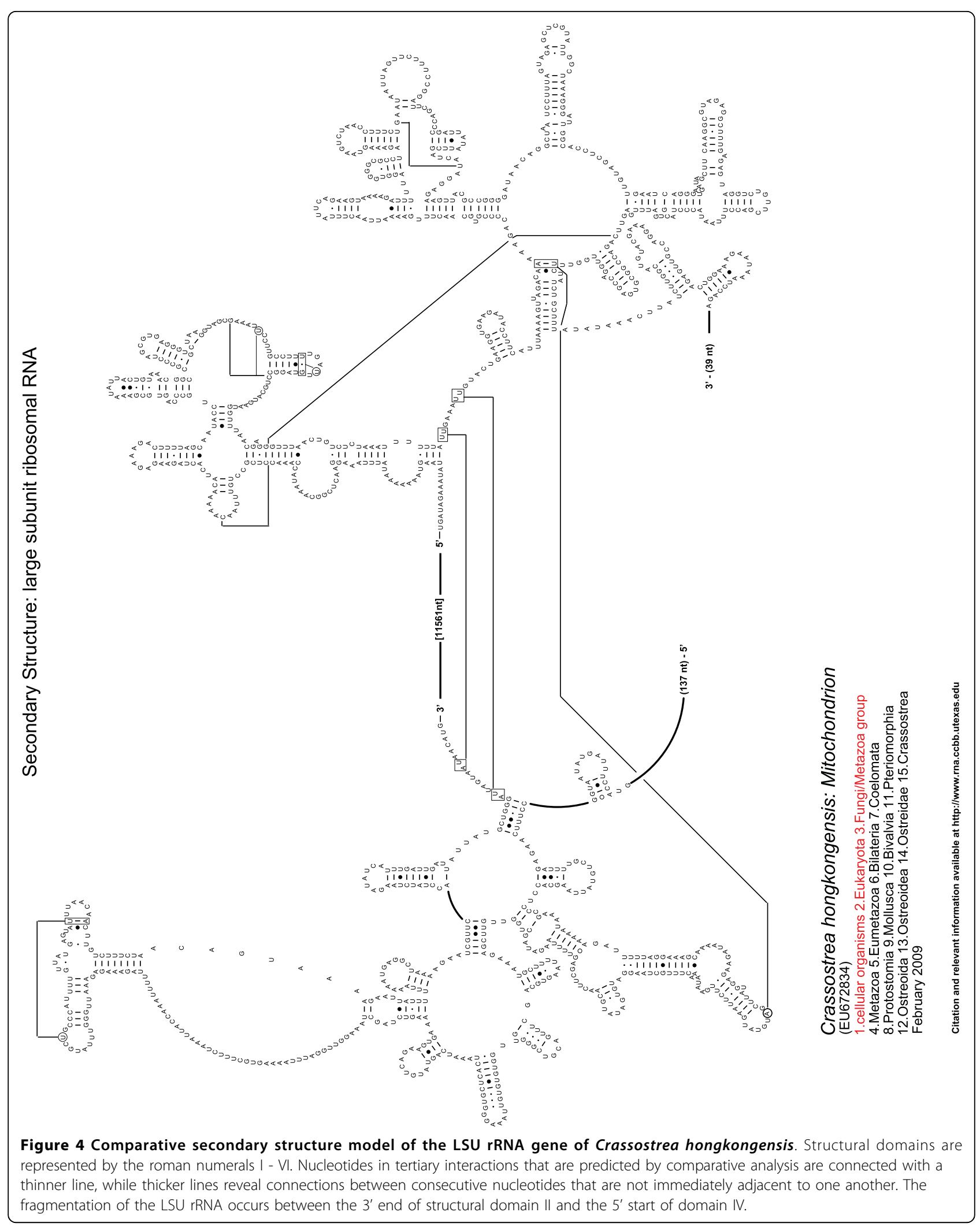


Table 2 Percent sequence similarity between Crassostrea virginica [42], C. gigas [42], and C. hongkongensis [43,44]

\begin{tabular}{lccc}
\hline LSU * & C. virginica & C. gigas & C. hongkongensis \\
\hline C. virginica & - & 65 & 65 \\
\hline C. gigas & 83 & - & 89 \\
\hline C. hongkongensis & 84 & 96 & -
\end{tabular}

* Similarities for the LSU $5^{\prime}$ and LSU $3^{\prime}$ are presented above and below the diagonal respectively.

rRNA secondary structures for C. virginica, C. gigas, and C. hongkongensis, respectively, and sequence similarities and characteristics are presented in Tables 2 and 3 .

In contrast to the 5' half of the molluscan LSU rRNA and other LSU rRNAs from organisms that span the tree of life, the 3' segment is more conserved among the molluscan rRNAs studied here and the 3' half of all LSU rRNA. The general conservation of the 5' and 3' halves of the molluscan LSU rRNA and all LSU rRNAs is consistent with the experimental studies that have associated more function to the 3' half than the 5' half. Although the oysters are closely related, interspecific sequence variation of the rRNAs is apparent (Table 2). The 5' half of the LSU rRNA is much more variable than the 3' half. The 3' LSU rRNA fragments in the three cupped oyster species have high nucleotide identity. C. gigas and C. hongkongensis are $\sim 96 \%$ identical, while $C$. virginica exhibits a slightly lower similarity with C. gigas (82\%) and C. hongkongensis (83\%). Consistent with larger phylogenetic analyses, the 5 ' fragments exhibit much lower similarities between the species than that observed in the 3' fragments. The C. virginica 5' fragment is only $65 \%$ identical with $C$. gigas. Yu et al. [43] do not report the 5' rRNA fragment, however it is included in GenBank: EU672834 by Ren et al. [44]. The C. hongkongensis 5' fragment is $64 \%$ identical with that of $C$. virginica and $89 \%$ identical with $C$. gigas.

Consistent with other studies on molluscan rRNA genes [51], the $\mathrm{A}+\mathrm{T}$ content is higher in the 5' versus 3' fragments (Table 3 ). The A+T content in the $5^{\prime} \mathrm{LSU}$

Table 3 Summary of large subunit molecular characteristics for Crassostrea virginica [42], C. gigas [42], and $C$. hongkongensis $[43,44]$

\begin{tabular}{cccc}
\hline & C. virginica & C. gigas & C. hongkongensis \\
\hline Large Subunit, 5' & & & \\
\hline Length (nt) & 748 & 587 & 605 \\
\hline Percent A+T & $66 \%$ & $69 \%$ & $68 \%$ \\
\hline Percent G+C & $34 \%$ & $31 \%$ & $32 \%$ \\
\hline Large Subunit, 3' & & & \\
\hline Length (nt) & 719 & 713 & 712 \\
\hline Percent A+T & $61 \%$ & $61 \%$ & $62 \%$ \\
\hline Percent G+C & $39 \%$ & $39 \%$ & $38 \%$ \\
\hline
\end{tabular}

rRNA fragment is $66 \%$ in C. virginica, $69 \%$ in C. gigas, and $68 \%$ in $C$. hongkongensis; however, the $\mathrm{A}+\mathrm{T}$ content in the 3' fragments of C. virginica and C. gigas is $61 \%$ and $62 \%$ in $C$. hongkongensis. The observed sequence similarities and phylogenetically consistent $\mathrm{A}+\mathrm{T}$ content [51] between fragmented and continuous LSU rRNA genes implies that the same selective pressure is actively maintaining the functionality of the genes. Thus, it is unlikely that these fragments represent ancestral remnants or degenerate genes.

While the LSU rRNA domains present in all three oyster species reveal significant conservation with other metazoan mitochondria, there are distinct differences apparent when compared to rRNA structures of bacteria, archaea, and nuclear-encoded eukaryotes. Lydeard et al. [51] presented a detailed phylogenetic analysis of molluscan mitochondrial LSU rRNA secondary structures for a chiton, two bivalves, six gastropods, and a cephalopod. Mollusks generally exhibit all six of the typical LSU rRNA structural domains including three characteristic helical features that are critical in inferring the phylogeny of mollusks. The three characteristic helical features considered in molluscan phylogeny are present in Domains II, III, and V and are highlighted in Figure 2 as features $a, b$, and $c$, respectively.

Combining thorough analysis of these features, in addition to identifying fragmentation of mitochondrial LSU fragmentation in other molluscan bivalves may allow for a more accurate determination of phylogenetic relationships. A recent evaluation of the 3' half of the LSU rRNA secondary structure in the family Pectinidae (Mollusca: Bivalvia) revealed high levels of conservation in the secondary structure [52] with limited taxa differentiation. However, incorporation of fragmentation analysis within and between family level analyses may demonstrate a more acute phylogenetic representation of molluscan bivalves.

The currently discussed fragmentation is characteristic of just one branch of molluscan phylogeny, thus it is a general characteristic at this time and difficult to determine the diagnostic significance regarding phylogenetic relationships. However, as more molluscan mitochondrial genomes are investigated, and additional unique characteristics in the rRNA structure are discovered, such as this fragmentation and the features discussed above [51], it may become possible to specifically determine taxonomic branches. It may also become possible to differentiate the branch of the Mollusca based upon patterns of fragmentation. Additional molluscan mtDNA genomic sequences are necessary to determine the phylogenetic significance of these structural features (including the fragmentation).

The fragmentation of the LSU rRNA occurs between the 3' end of structural domain II and the 5' start of 
domain IV. Domain III is completely deleted; for comparison, domain III is composed of approximately 360 nucleotides in the bacterium $E$. coli. While its variation is limited in size and structure in the bacteria, archaea, and eukaryotes [17], fragmentation has been observed in different locations in domain III in a few eukaryotic nuclear-encoded rRNAs (for example, in the insect Apis mellifera [53]), and a few protists (such as Euglena gracilis [54]), and Trypanosoma brucei (X14553) [17]). Domain III is significantly truncated in size in bilateral animal mitochondria. Vertebrates typically maintain part of domain III, while some invertebrates such as C. elegans lack all, or nearly all, of domain III $[17,55]$.

The peptide exit tunnel (PET) for growing proteins during protein synthesis in the $50 \mathrm{~S}$ ribosomal subunit has been studied previously [56,57], which maps to the five domains of the LSU rRNA (Figure 5; red and green nucleotide positions are the regions associated with PET) and transverses through the 50S crystal structure (Haloarcular marismortui, PDB ID 1JJ2) [58]. The PET starts near the middle of this subunit at the peptidyl transferase center (PTC) and extends to the lower back of the $50 \mathrm{~S}$ ribosomal subunit. The regions in domains II, IV, and V (red nucleotides) of the $H$. marismortui LSU rRNA associated with PET are present in all of the LSU rRNAs that span the tree of life while the regions in domains I and III (green nucleotides) are not present in the LSU rRNAs in the three Crassostrea mitochondrial genomes. In particular, domain III - immediately 3' to the end of the 5' LSU rRNA fragment and 5' to the start of the 3' LSU rRNA fragment - maps to the end of PET at the lower back of the $H$. marismortui $50 \mathrm{~S}$ ribosomal subunit (Figure 6; regions shown in purple). Thus the fragmentation of the oyster mitochondrial LSU rRNA occurs at one of the regions associated with PET that is deleted in these oyster LSU rRNAs. Interestingly, the deleted domains I and III in a cryo-EM structure of a mammalian mitochondrial ribosome were not replaced with ribosomal proteins nor with other portions of LSU rRNA [59]. Consequently, the absence of domains I and III (green and purple in Figure 6, respectively) shortens the exit tunnel by $25 \AA$ compared to the bacterial PET of $\sim 88 \AA$, suggesting that a growing peptide will be prematurely exposed to solvent as indicated by the cryoEM structure. Currently it is not obvious why the fragmentation in the oyster LSU rRNAs occurs at the site directly involved in the formation of PET.

Nearly all of the other identified fragmentations of the rRNA genes contain a set of base pairings that form a helix that connects the two (or more) fragments of rRNA. Although no helix that is conserved in the three Crassostrea connect the two oyster LSU rRNA fragments, many tertiary interactions connect all regions of the LSU rRNA with one another in the high resolution crystal structures of the $50 \mathrm{~S}$ ribosomal subunit (see the CRW links $[17,60]$ which exhibit an interactive flash secondary structure browser and tables that reveal all of the secondary and tertiary interactions in the rRNA crystal structures, http://www.rna.ccbb.utexas.edu/SAE/ 2A/RNA2DMap/index.php, and http://www.rna.ccbb. utexas.edu/SAE/2A/xtal_Info/). Lastly, the ribosomal proteins interact with the rRNA and with one another to stabilize the network of interactions that provide the overall stability and dynamic behavior of the ribosome during protein synthesis. Thus the fragmentation in the rRNA, especially in a highly variable region, should not affect the structure nor the function of the ribosome since many organisms as noted in the introduction are fragmented and are functional.

Though several models have been developed, the evolutionary pathways responsible for fragmentation of mitochondrial ribosomal genes remain unknown. Several hypotheses have been developed for each organism in which fragmentation has been observed. For example, within just Chlamydomonads, it has been proposed that gene fragmentation has occurred by a bacterial-like transposition [28,61], recombination [28,29,62], horizontal transfer [63], acquisition and scrambling of processing sites [29], or it could be that the primordial ribosome was actually a noncovalent network of small RNA molecules [23,28]. As there are similarities in the degree of variability and regions that are excised, Schnare et al. [64] suggest that an ancestral ability to excise spacers within regions of variability may have been evolutionarily maintained within ciliates such as $T$. pyriformis. The evolutionary pathway that lead to oyster mtDNA LSU rRNA fragmentation is difficult to determine at this time due to the small number of fragmentations in the metazoans.

Discontinuous mitochondrial rRNA genes are rare in metazoans. Beyond the fragmented rRNA in oysters, the only other documented example of a fragmented mitochondrial rRNA is in the non-bilateral Trichoplax adhaerens and three other Placozoans [45,46,65] the simplest known free-living animal. For comparison with the oysters, we have generated secondary structures for these four Placozoan LSU rRNAs. We present one secondary structure here (Figure 7) and the remaining three are on the Comparative RNA Website). The LSU rRNAs from the Placozoans contain many of the structural elements present in Bacteria that are however absent in the bilateral animal LSU rRNAs. This contrasts with the bilateral animal mitochondrial LSU rRNAs which are highly truncated in comparison with the nuclear-encoded LSU rRNAs of Bacteria, Archaea, and Eukaryotes.

While the fragmentation and large truncation of the oyster mitochondrial LSU rRNA (that have been studied herein) occur between positions 1275-1650 (domains III 


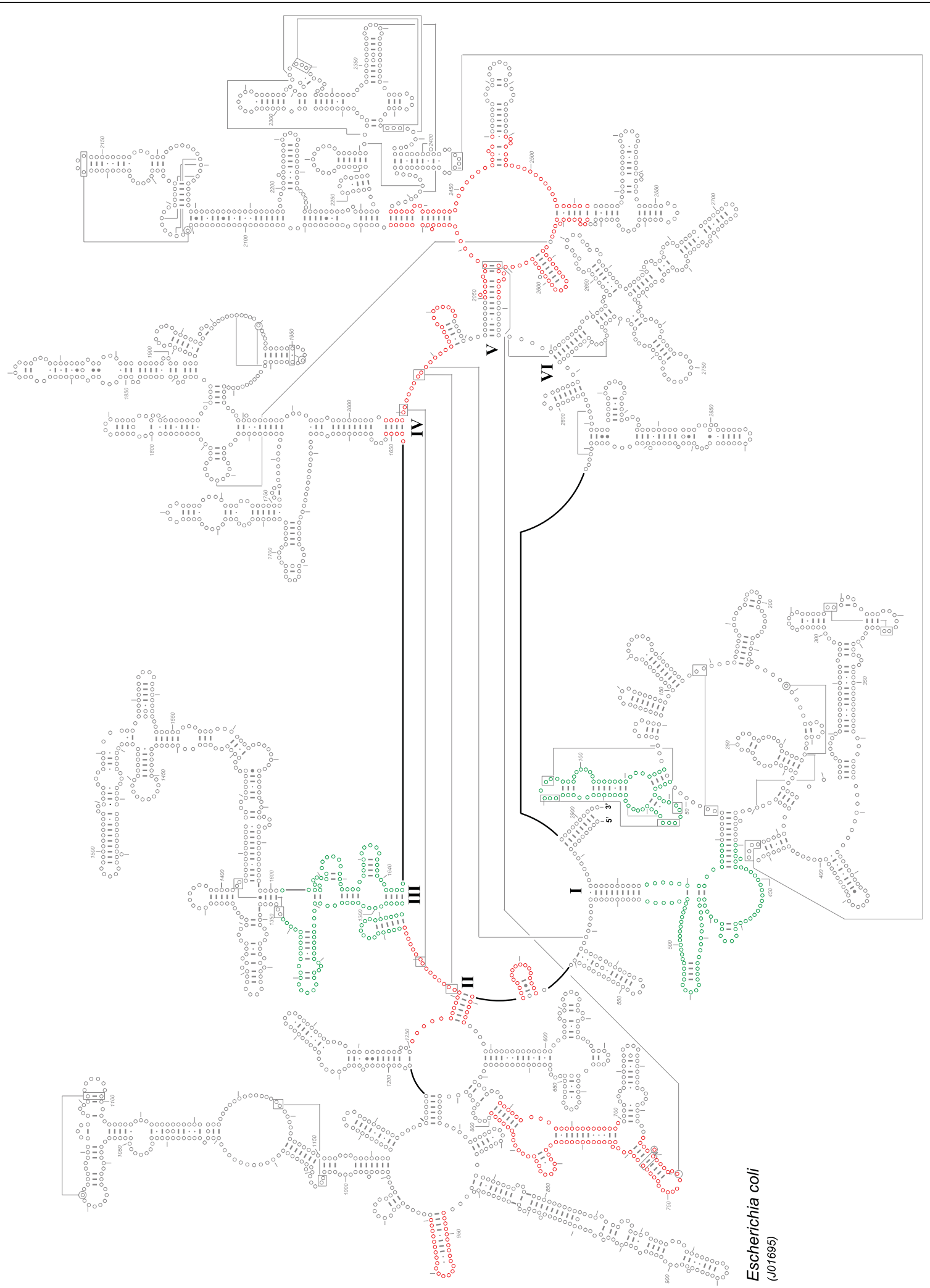

Figure 5 Escherichia coli 235 rRNA [17]. Regions that form the protein exit tunnel in the LSU ribosomal subunit are colored, red for the regions present in all of the LSU rRNAs that span the tree of life and green for the regions that are deleted in the oyster mitochondrial LSU rRNAs. 


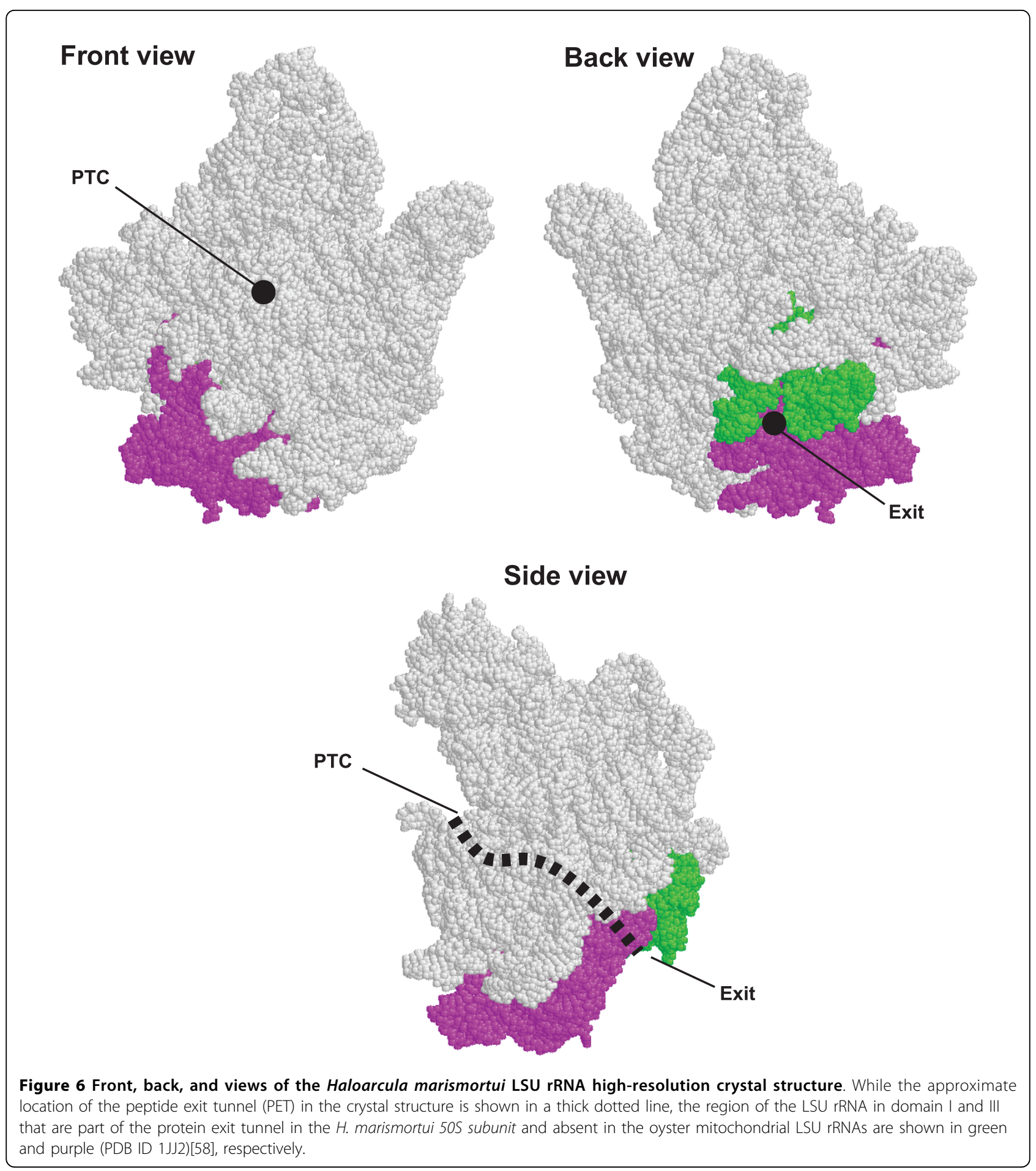

and IV), all four Placozoan LSU rRNAs are fragmented after position 1013 (Escherichia coli numbering). This region of the rRNA is variable, consistent with a split in the rRNA without subsequent ligation. One of the Placozoan LSU rRNA structures (BZ10101) also had an insertion after position 1787, a region that is conserved in rRNAs that span the entire tree of life (including the mitochondria and chloroplast). This insertion was identified earlier [65] as a group II intron. Our analysis reveals that this intron appears to be in $B$ subgroup of the group II introns. Two other introns occur after 1787. Both are mitochondrial, both are also group IIB, one is a green algae, Pedinomonas minor (AF116775) and the second is a brown algae, Pylaiella littoralis 


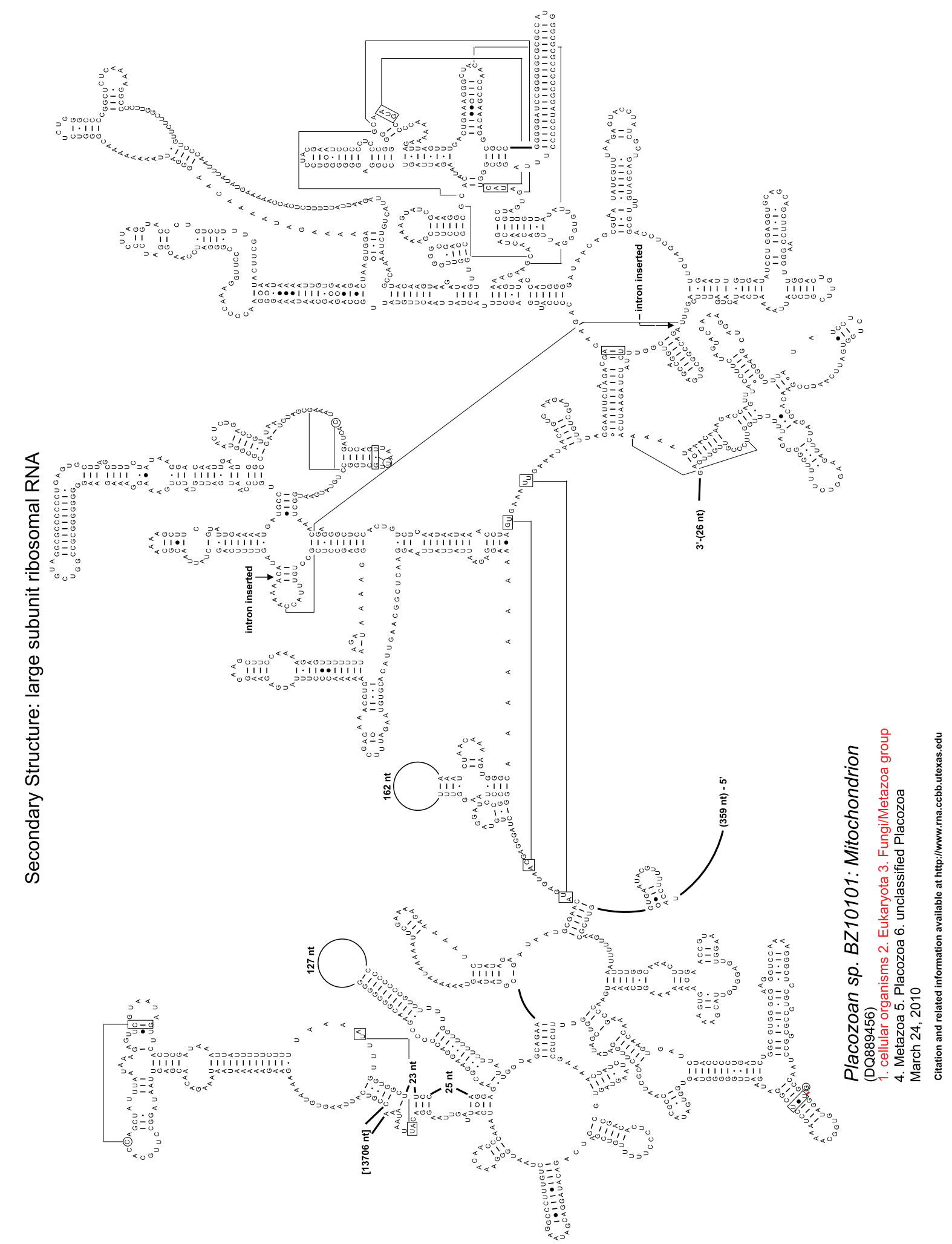

Figure 7 Comparative secondary structure model of the LSU rRNA gene of the Placozoan species (BZ10101). Nucleotides in tertiary interactions that are predicted by comparative analysis are connected with a thinner line, while thicker lines reveal connections between consecutive nucleotides that are not immediately adjacent to one another. The position of the LSU rRNA fragmentation and the location of the group II intron are noted. 
(Z48620). A third insertion in some of the Placozoan LSU rRNAs occurs after position 2586, which is in the peptidyl transferase loop, one of the most conserved regions in the rRNA. This intron, also identified previously [65] as a group II intron, also appears to be in the B subgroup. This is the first occurrence of an intron that we are aware of at this position. However many introns occur in the peptidyl transferase site, including at positions 2584 and 2585 http://www.rna.ccbb.utexas. edu/SAE/2C/rRNA_Introns/table1.php?show=condensed\&from_gene $=23 S[17,20]$.

The bilateral animals have on average about $16 \mathrm{kbp}$ in their mitochondria. Their genomes are very compact, coding for approximately 37 genes that are in general truncated in size in comparison with Bacteria, Archaea, Eukaryotic nuclear-encoded and chloroplast, and with a minimal number of nucleotides not coding for protein or RNA between genes [66]. While the Cnidaria, Demospongiae, and Hexactinellida non-bilateral genomes are just slightly larger than the bilateral genomes (16 kbp - $25.6 \mathrm{kbp}$ ), the Placozoa non-bilateral genomes range from approximately $32 \mathrm{kbp}-43 \mathrm{kbp}$ [66]. The Placozoan and a few of the other non-bilateral animals have multiple introns in their cytochrome oxidase subunit 1 and NADH dehydrogenase subunit 5 protein-coding genes, while none of the bilateral animal genomes have introns [46]. Phylogenetic analysis of the non-bilateral and bilateral Metazoan place the non-bilateral organisms on one branch and the bilateral on a separate major branch of the phylogenetic tree $[46,67,68]$. Although introns and trans-splicing have been observed in the Placozoan mitochondria, that have the largest animal mitochondrial genomes, we were not surprised that none were found (as discussed earlier) in the oyster genomes as their genome is typical in size and content with the other bilateral animal mitochondrial genomes.

Previous analysis of molluscan phylogeny has identified three particular mitochondrial LSU rRNA structural features that provide a phylogenetic signal [51]. The presence and/or absence of stem-loop structures within the LSU rRNA, as well length variation, previously resulted in a phylogenetic re-structuring of the molluscan taxa. Of the eleven mollusks (and Drosophila melanogaster) evaluated by Lydeard et al. [51], none of them exhibit the same characteristics as observed in the oysters and the fragmentation is unique. The phylogenic segregation from the predicted molluscan taxonomy warrant further examination and the fragmentation of the LSU rRNA gene in the oysters should be considered in future evaluation of molluscan phylogeny.

\section{Conclusions}

Although many examples of discontinuous ribosomal genes have been documented in bacteria and archaea, as well as the nuclei, chloroplasts, and mitochondria of eukaryotes, oysters are the first characterized examples of fragmented bilateral animal mitochondrial rRNA genes. This study presents the secondary structure models of the discontinuous ribosomal RNA genes in the three cupped oyster (Crassostrea) mitochondrial genomes. Comparative structure models for the large subunit rRNA in each of the three oyster species are generally similar to those for other bilateral metazoans. While modeling the rRNA structure of the oyster, we determined that several of the rRNA secondary structure regions associated with the exit tunnel (identified in the high-resolution crystal structure of Haloarcular marismortui, PDB \# 1JJ2) were in fact absent in the oyster mitochondrial LSU rRNA secondary structure. The biological and structural significance of this observation is not readily apparent.

To date the only other examples of discontinuous mitochondrial rRNA genes in Metazoans have been documented in Placozoans, which are considered to be the most primitive animals. We have generated comparative secondary structure models for several Placozoans LSU rRNAs (available at our supplemental site http://www.rna.ccbb.utexas.edu/SIM/4A/Fragmented_Mollusk/. While the fragmentation in the oyster and Placozoan mitochondrial LSU rRNA occurs in highly variable regions, consistent with other rRNA fragmentations, the specific location of the fragmentation is different between the species. Additionally, some Placozoans contain at least one group II intron. For the oysters involved in our studies, DNA sequence signatures, secondary structure analysis, RT-PCR experimentation, analysis of EST databases, and the absence of intron sequence and structural features all strongly suggest that these oyster mitochondrial rRNA fragments associate noncovalently to form a functional ribosome.

\section{Methods}

\section{Reverse-transcriptase analysis}

Ribonucleic acid (RNA) and deoxyribonucleic acid (DNA) were individually extracted from adductor muscle of the oyster Crassostrea virginica and the bay scallop Argopecten irradians using the RNeasy Mini kit (Qiagen) and the DNeasy Blood \& Tissue kit (Qiagen), respectively, per manufacturer's instructions. Reversetranscriptase (RT)-PCR was performed on the C. virginica and $A$. irradians RNA to generate complementary DNA (cDNA), using the High Capacity RNA-to-cDNA kit (Applied BioSystems Inc).

PCR amplification was performed to amplify portions of the 5' half and 3' halves of the LSU rRNA genes from both the DNA and cDNA templates. Three amplicons were investigated: 1) a $233 \mathrm{bp}$ portion of the 5' half of the LSU rRNA gene, 2) and 434 bp portion of the 3' 
half of the rRNA LSU gene, and 3) a 748-773 bp amplicon that spans from the 5 ' portion into the 3 ' portion of the rRNA LSU gene. Primers for each of the three regions PCR amplicons are presented in Table 1. The third set of primers, though located in regions of conservation, are degenerate in order to amplify both $C$. virginica and A. irradians (GenBank: DQ665851). If the 5' and 3' fragments of the rRNA LSU are indeed splice post-transcriptionally, a $\sim 773$ bp amplicon will be amplified in the cDNA template of the oyster though not from its associated DNA template. The amplification of a $748 \mathrm{bp}$ region of the fully contiguous LSU rRNA gene in A. irradians [47] in both genomic DNA and CDNA, serves as a positive control for the PCR reaction.

PCR was performed on an Eppendorf MasterCycler EP thermocycler using annealing temperatures defined in Table 1 . The GoTaq polymerase system was employed with the following reagent conditions: $1 \mathrm{X}$ manufacturer supplied Flexi-PCR buffer (Promega Corporation), 1.5 $\mathrm{mM} \mathrm{MgCl} 2,0.2 \mathrm{mM}$ dNTPs, $0.2 \mu \mathrm{M}$ primers, $5 \mathrm{U} / \mu \mathrm{l}$ GoTaq $^{\circ}$ DNA polymerase (Promega Corporation). Approximately $50 \mathrm{ng}$ of genomic DNA or $100 \mathrm{ng}$ of cDNA template were incorporated in each reaction. PCR amplicons were visualized after agarose gel electrophoresis (with ethidium bromide staining). Final amplicons were Sanger sequenced to ensure amplification of the target region from both the DNA and cDNA template.

\section{Secondary Structure Modeling}

The $C$. virginica mitochondrial genome [GenBank: AY905542][42] and that of C. gigas [GenBank: AF177226] were used to facilitate gene annotation and to generate putative secondary structures for each of the ribosomal genes. The recently published $C$. hongkongensis mitochondrial genomes from $\mathrm{Yu}$ et al. [43] [GenBank: EU266073] and Ren et al. [44] [GenBank: EU672834] were compared, particularly in regard to the rRNA gene content. EST collections for $C$. virginica and C. gigas, which contain numerous mitochondrial transcripts, were used to infer gene boundaries. EST databases were managed using SEQtools 8.1 [69] http://www. seqtools.dk.

The Comparative RNA Website and Rfam were employed to screen the mtDNA genome of the oyster for introns. Rfam [48] utilizes a nucleotide database (RFAMSEQ) of structural RNA sequences (including non-coding RNA genes and cis-regulatory RNA elements) to identify particular families of RNAs. Regions of the C. virginica mitochondrial genome denoted as non-coding regions were screened for introns that might mediate the splicing of the discontinuous LSU rRNA gene.
Secondary structure models were determined for the mitochondrial LSU rRNA genes of $C$. virginica, C. gigas, and $C$. hongkongensis using comparative structure models for LSU rRNAs from organisms that span the entire tree of life including animal mitochondrial rRNAs [17]. The prediction of several RNAs' secondary structure with comparative analysis is based on a very simple but profound concept. Each of the different types of RNA - e.g. tRNA, 5 S, SSU, and LSU rRNA form a similar secondary and three-dimensional structure, although the underlying primary structure, or sequence, can be significantly different.

Transfer RNA was the first molecule analyzed with this method once the first few tRNA sequences were determined in the early 1960's [70-74]. At the onset of these studies, a small number of sequences (e.g. tRNA) were inspected for similar helices that are present in the same region of the rRNA. The classic cloverleaf structure for the tRNA was determined to be that structure common to a growing number of tRNA sequences. The tRNA crystal structures [75,76] verified this cloverleaf secondary structure that was predicted with comparative methods.

This success with tRNA encouraged the use of comparative methods to predict other RNA secondary structures. The comparative structure for $5 \mathrm{~S}$ rRNA was determined by Fox and Woese [77,78]. The prediction of the $16 \mathrm{~S}$ and $23 \mathrm{~S}$ rRNA secondary structures models with comparative analysis started after the first few bacterial sequences were determined in the early 1980's $[79,80]$. All of these early comparative studies on these RNA (and others not mentioned) were performed with a visual analysis of the RNA sequences for common structure. However, as the number of sequences increased, and larger sequences (e.g. 16S and 23S rRNA) were studied, these sequences were aligned for maximum sequence identity. Base pairs were predicted for those columns in an alignment that have similar patterns of variation, more commonly called covariation. In parallel, a series of computational methods were developed to identify and quantify the significance and purity of these covariations $[17,18,81,82]$. Initially we developed a simple number pattern method [18], followed by more sophisticated chi-square based methods [83] and mutual information [81,84] Many other comparative methods have been developed. A partial list is in Gardner and Giegerich [85]. Hidden Markov Models have also been used to predict RNA structure [86,87]. Other quantitative methods have been developed in the Gutell lab $[17,82]$. The determination of the proper alignment and secondary structure occur in parallel. Sequences in the alignment can be realigned once a common structural element is identified for a set of sequences that do not have sufficient sequence identity. Here these sequences are then aligned to maintain similarity in structure. 
While an analysis of sequences from organisms that spanned the entire tree of life revealed parts of the rRNA that are conserved in primary and secondary structure, this analysis also revealed sequences and secondary structural elements that are only common to a subset of RNAs under study. These patterns of the variation and conservation in the rRNA are characteristic of an organism or group of organisms' location on the phylogenetic tree. The determination of the common secondary structure proceeds in stages. Each secondary structure model is considered a hypothesis that is tested with each new sequence. As the number and diversity in the sequences increases, the structure models are modified. Some previously proposed base pairings are removed when both positions of a predicted base pair do not have a similar pattern of variation while new base pairs are predicted relative to the increase in the number and variation in sequences when analyzed with improved, more sensitive covariation algorithms. Every secondary structure model is not determined de novo; instead every new secondary structure we model with comparative analysis is derived from the previously proposed secondary structures that are the most similar in sequence. Thus, as this determination of secondary structures proceeds from the root of the tree to the outer branches, the newly determined secondary structure has less and less variation from the template structure it is derived from. The Comparative RNA Website (CRW) [17], http://www.rna.ccbb.utexas.edu contains more than 1000 rRNA secondary structure diagrams. More secondary structure diagrams are continually determined to increase the sampling of organisms that span the entire tree of life, thus capturing more of the variations that are usually diagnostic of a group of related organisms. Molluscan rRNA structures determined previous [51] were used to derive the comparative structure models of the oyster mitochondrial rRNAs. Additional details for the methods and predicted structure models are available at the CRW http://www. rna.ccbb.utexas.edu/, http://www.rna.ccbb.utexas.edu/ CAR/1D/; the CRW contains supplemental information http://www.rna.ccbb.utexas.edu/SIM/4A/Fragmented_Mollusk/.

\footnotetext{
Acknowledgements

We would like to thank the reviewers for their comments and critiques. We thank Barbara Hidalgo-Sotelo for her work on the initial rRNA alignments. This work was supported by the National Institutes of Health (GM067317 to R.R.G.) and the Welch Foundation (F-1427 to R.R.G.).
}

\section{Author details}

${ }^{1}$ College of Earth, Ocean, and Environment, University of Delaware, Lewes, DE, USA. ${ }^{2}$ Center for Computational Biology and Bioinformatics, The Institute for Cellular and Molecular Biology, University of Texas, Austin, TX, USA.

${ }^{3}$ Dana-Farber Cancer Institute, Harvard Medical School, Boston, MA, USA.

\section{Authors' contributions}

CAM carried out the molecular genetic assays, participated in the sequence annotation, and drafted the manuscript. JJC and JCL modeled the secondary rRNA structures and contributed to the preparation of the manuscript. PMG has made substantial contributions to project design, analysis and interpretation of data, and revision of this manuscript. RRG oversaw the secondary structure modeling and contributed to the preparation of the manuscript. All authors read and approved the final manuscript.

Received: 27 October 2009 Accepted: 2 September 2010

Published: 2 September 2010

\section{References}

1. Alberts B, Bray D, Lewis J, Raff M, Roberts K, Watson JD: Molecular Biology of the Cell. New York: Garland Publishing, Inc., 31983.

2. Sloof P, Van den Burg J, Voogd A, Benne A, Agostinelli M, Borst P, Gutell R, Noller HF: Further characterization of the extremely small mitochondrial ribosomal RNAs from trypanosomes: a detailed comparison of the 95 and 125 RNAs from Crithidia fasciculata and Trypanosoma brucei with rRNAs from other organisms. Nucl Acids Res 1985, 13:4171-4191.

3. Chao $S$, Sederoff $R$, Levings $C$ : Nucleotide sequence and evolution of the $18 \mathrm{~S}$ ribosomal RNA gene in maize mitochondria. Nucl Acids Res 1984, 12:6629-6644.

4. Dale RM, Mendu N, Ginsburg H, Kridl JC: Sequence analysis of the maize mitochondrial 26S rRNA gene and flanking regions. Plasmid 1984, 11:141-150.

5. Spencer DF, Bonen L, Gray MW: Primary sequence of wheat mitochondrial $5 \mathrm{~S}$ ribosomal ribonucleic acid: functional and evolutionary implications. Biochem 1981, 20:4022-4029.

6. Lang BF, Goff $L J$, Gray MW: A $5 S$ rRNA gene is present in the mitochondrial genome of the protist Reclinomonas americana but is absent from red algal mitochondrial DNA. J Mol Biol 1996, 261:607-613.

7. Turmel M, Lemieux C, Burger G, Lang BF, Otis C, Plante I, Gray MW: The complete mitochondrial DNA sequences of Nephroselmis olivacea and Pedinomonas minor: two radically different evolutionary patterns within green algae. Plant Cell 1999, 11:1717-1730.

8. Turmel M, Otis C, Lemieux C: The complete mitochondrial DNA sequence of Mesostigma viride identifies this green alga as the earliest green plant divergence and predicts a highly compact mitochondrial genome in the ancestor of all green plants. Mol Biol Evol 2002, 19:24-38.

9. Turmel M, Otis C, Lemieux C: The chloroplast and mitochondrial genome sequences of the charophyte Chaetosphaeridium globosum: Insights into the timing of the events that restructured organelle DNAs within the green algal lineage that led to land plants. Proc Natl Acad Sci USA 2002, 99:11275-11280.

10. Burger G, Saint-Louis D, Gray MW, Lang BF: Complete sequence of the mitochondrial DNA of the red alga Porphyra purpurea: cyanobacterial introns and shared ancestry of red and green algae. Plant Cell 1999, 11:1675-1694.

11. Wolff $G$, Plante I, Lang BF, Kück U, Burger G: Complete sequence of the mitochondrial DNA of the chlorophyte alga Prototheca wickerhamii: gene content and genome organization. J Mol Biol 1994, 237:75-86.

12. Ohta N, Sato N, Kuroiwa T: Structure and organization of the mitochondrial genome of the unicellular red alga Cyanidioschyzon merolae deduced from the complete nucleotide sequence. Nucl Acids Res 1998, 26:5190-5298.

13. Oudot-Le Secq MP, Fontaine JM, Rousvoal S, Kloareg B, Loiseaux-de Goer S: The complete sequence of a brown algal mitochondrial genome, the ectocarpale Pylaiella littoralis (L.) Kjellm. J Molec Evol 2001, 53:80-88.

14. Oudot-le Secq MP, Kloareg B, Loiseaux-de Goer S: The mitochondrial genome of the brown alga Laminaria digitata: a comparative analysis. European Journal of Phycology 2002, 37:163-172.

15. Gray MW, Lang BF, Burger G: Mitochondria of protists. Annu Rev Gen 2004, 38:477-524.

16. Bullerwell CE, Schnare MN, Gray MW: Discovery and characterization of Acanthamoeba castellanii mitochondrial 5 S rRNA. RNA - a Publication of the RNA Society 2003, 9:287-292.

17. Cannone J, Subramanian S, Schnare M, Collett J, D'Souza L, Du Y, Feng B, Lin N, Madabusi L, Muller K, et al: The Comparative RNA Web (CRW) Site: an online database of comparative sequence and structure information for ribosomal, intron, and other RNAs. BMC Bioinformatics 2002, 3:2. 
18. Gutell RR, Weiser B, Woese CR, Noller HF: Comparative anatomy of 16Slike ribosomal RNA. Progress in Nucleic Acid Research and Molecular Biology 1985, 32:155-216.

19. Kruger K, Grabowski PJ, Zaug AJ, Sands J, Gottschling DE, Cech TR: Selfsplicing RNA: autoexcision and autocyclization of the ribosomal RNA intervening sequence of Tetrahymena. Cell 1982, 31:147-157.

20. Jackson SA, Cannone JJ, Lee JC, Gutell RR, Woodson SA: Distribution of rRNA introns in the three-dimensional structure of the ribosome. $J \mathrm{Mol}$ Biol 2002, 323:35-52.

21. Trust TJ, Logan SM, Gustafson CE, Romanik PJ, Kim NW, Chan VL, Ragan MA, Guerry P, Gutell RR: Phylogenetic and molecular characterization of a $23 \mathrm{~S}$ rRNA gene positions the genus Campylobacter in the epsilon subdivision of the Proteobacteria and shows that the presence of transcribed spacers in common in Campylobacter spp. Journal of Bacteriology 1994, 176:4597-4609.

22. Kim NW, Gutell RR, Chan VL: Complete sequences and organization of the rrnA operon from Campylobacter jejuni TGH9011 (ATCC43431). Gene 1995, 164:101-106.

23. Gray MW, Schnare MN: Evolution of rRNA gene organization. In Ribosomal RNA: Structure, evolution, processing, and function in protein biosynthesis. Edited by: Zimmermann R, Dahlberg A. Boca Raton: CRC Press; 1996:49-69.

24. Evguenieva-Hackenberg E: Bacterial ribosomal RNA in pieces. Molec Microbiol 2005, 57:318-325.

25. Forget L, Ustinova J, Wang Z, Huss VAR, Franz Lang B: Hyaloraphidium curvatum: A linear mitochondrial genome, tRNA editing, and an evolutionary link to lower fungi. Mol Biol Evol 2002, 19:310-319.

26. Heinonen T, Schnare M, Young P, Gray M: Rearranged coding segments, separated by a transfer RNA gene, specify the two parts of a discontinuous large subunit ribosomal RNA in Tetrahymena pyriformis mitochondria. J Biol Chem 1987, 262:2879-2887.

27. Burger G, Zhu Y, Littlejohn TG, Greenwood SJ, Schnare MN, Lang BF, Gray MW: Complete sequence of the mitochondrial genome of Tetrahymena pyriformis and comparison with Paramecium aurelia mitochondrial DNA. J Mol Biol 2000, 297:365-380.

28. Boer PH, Gray MW: Scrambled ribosomal RNA gene pieces in Chlamydomonas reinhardtii mitochondrial DNA. Cell 1988, 55:399-411.

29. Denovan-Wright EM, Lee RW: Comparative structure and genomic organization of the discontinuous mitochondrial ribosomal RNA genes of Chlamydomonas eugametos and Chlamydomonas reinhardtii. J Mol Biol 1994, 241:298-311.

30. Denovan-Wright EM, Sankoff D, Spencer DF, Lee RW: Evolution of fragmented mitochondrial ribosomal RNA genes in Chlamydomonas. Journal of Molecular Evolution 1996, 42:382-391.

31. Nedelcu AM, Spencer DF, DenovanWright EM, Lee RW: Discontinuous mitochondrial and chloroplast large subunit ribosomal RNAs among green algae: Phylogenetic implications. Journal of Phycology 1996, 32:103-111.

32. Kroymann J, Zetsche K: The mitochondrial genome of Chlorogonium elongatum inferred from the complete sequence. J Molec Evol 1998, 47:431-440.

33. Kairo A, Fairlamb AH, Gobright E, Nene V: A $7.1 \mathrm{~kb}$ linear DNA molecule of Theileria parva has scrambled rDNA sequences and open reading frames for mitochondrially encoded proteins. EMBO J 1994, 13:898-905.

34. Feagin JE, Gardner MJ, Williamson DH, Wilson RJM: The putative mitochondrial genome of Plasmodium-Falciparum. J Protozool 1991, 38:243-245.

35. Gillespie D, Salazar N, Rehkopf D, Feagin J: The fragmented mitochondrial ribosomal RNAs of Plasmodium falciparum have short A tails. Nucl Acids Res 1999, 27:2416-2422.

36. Feagin JE: Mitochondrial genome diversity in parasites. Int/ J Parasitol 2000, 30:371-390.

37. Nash EA, Nisbet RER, Barbrook AC, Howe CJ: Dinoflagellates: a mitochondrial genome all at sea. Trends in Genetics 2008, 24:328-335.

38. Waller RF, Jackson CJ: Dinoflagellate mitochondrial genomes: stretching the rules of molecular biology. BioEssays 2009, 31:237-245.

39. Jackson C, Norman J, Schnare M, Gray M, Keeling P, Waller R: Broad genomic and transcriptional analysis reveals a highly derived genome in dinoflagellate mitochondria. BMC Biology 2007, 5:41.

40. Slamovits $\mathrm{CH}$, Saldarriaga JF, Larocque A, Keeling PJ: The Highly Reduced and Fragmented Mitochondrial Genome of the Early-branching Dinoflagellate Oxyrrhis marina Shares Characteristics with both
Apicomplexan and Dinoflagellate Mitochondrial Genomes. Journal of Molecular Biology 2007, 372:356-368.

41. Kamikawa R, Inagaki Y, Sako Y: Fragmentation of Mitochondrial Large Subunit rRNA in the Dinoflagellate Alexandrium catenella and the Evolution of rRNA structure in Alveolate Mitochondria. Protist 2007, 158:239-245

42. Milbury CA, Gaffney PM: Complete mitochondrial DNA sequence of the eastern oyster Crassostrea virginica. Marine Biotechnology 2005, 7:697-712

43. Yu Z, Wei Z, Kong X, Shi W: Complete mitochondrial DNA sequence of oyster Crassostrea hongkongensis - a case of "Tandem duplicationrandom loss" for genome rearrangement in Crassostrea? BMC Genomics 2008, 9:477.

44. Ren J, Liua X, Zhanga G, Liu B, Guo X: "Tandem duplication-random loss" is not a real feature of oyster mitochondrial genomes: comment. $B M C$ Genomics 2009, 10:1-6.

45. Dellaporta SL, Xu A, Sagasser S, Jakob W, Moreno MA, Buss LW Schierwater B: Mitochondrial genome of Trichoplax adhaerens supports Placozoa as the basal lower metazoan phylum. Proceedings of the National Academy of Sciences 2006, 103:8751-8756.

46. Signorovitch AY, Buss LW, Dellaporta SL: Comparative genomics of large mitochondria in Placozoans. PLoS Genetics 2007, 3:e13.

47. Ren J, Shen X, Jiang F, Liu B: The mitochondrial genomes of two scallops, Argopecten irradians and Chlamys farreri (Mollusca: Bivalvia): the most highly rearranged gene order in the Family Pectinidae. Journal of Molecular Evolution 2010, 70:57-68.

48. Gardner PP, Daub J, Tate JG, Nawrocki EP, Kolbe DL, Lindgreen S, Wilkinson AC, Finn RD, Griffiths-Jones S, Eddy SR, Bateman A: Rfam: updates to the RNA families database. Nucl Acids Res 2009, 37:D136-140.

49. Gutell RR, Fox GE: A compilation of large subunit RNA sequences presented in a structural format. Nucl Acids Res 1988, 16:R175-R269.

50. Gutell RR, Larsen N, Woese CR: Lessons from an evolving rRNA: $16 \mathrm{~S}$ and 235 rRNA structures from a comparative perspective. Micro Rev 1994, 58:10-26.

51. Lydeard C, Holznagel WE, Schnare MN, Gutell RR: Phylogenetic analysis of molluscan mitochondrial LSU rDNA sequences and secondary structures. Molecular Phylogenetics and Evolution 2000, 15:83-102.

52. Salvi D, Bellavia G, Cervelli M, Mariottini P: The analysis of rRNA sequencestructure in phylogenetics: An application to the family Pectinidae (Mollusca: Bivalvia). Molecular Phylogenetics and Evolution 2010, 56:1059-1067.

53. Gillespie JJ, Johnston JS, Cannone JJ, Gutell RR: Characteristics of the nuclear (18 S, $5.8 \mathrm{~S}, 28 \mathrm{~S}$ and 5S) and mitochondrial (12S and 16S) rRNA genes of Apis mellifera (Insecta:Hymenoptera): structure, organization, and retrotransposable elements. Insect Molecular Biology 2006, 15:657-686.

54. Gray MW, Schnare MN: Evolution of the Modular Structure of rRNA. In The Ribosome: Structure, Function, \& Evolution. Edited by: Warner JR. Washington DC: American Society for Microbiology; 1990:589-597.

55. Michot B, Qu L, Bachellerie J: Evolution of large-subunit rRNA structure: The diversification of divergent D3 domain among major phylogenetic groups. European Journal of Biochemistry 1990, 188:219-229.

56. Frank J, Zhu J, Penczek P, Li Y, Srivastava S, Verschoor A, Radermacher M, Grassucci R, Lata RK, Agrawal RK: A model of protein synthesis based on cryo-electron microscopy of the E. coli ribosome. Nature 1995, 376:441-444.

57. Nissen P, Hansen J, Ban N, Moore PB, Steitz TA: The Structural Basis of Ribosome Activity in Peptide Bond Synthesis. Science 2000, 289:920-930.

58. Ban N, Nissen P, Hansen J, Moore PB, Steitz TA: The complete atomic structure of the large ribosomal subunit at 2.4 angstrom resolution. Science 2000, 289:905-920.

59. Sharma MR, Koc EC, Datta PP, Booth TM, Spremulli LL, Agrawal RK: Structure of the Mammalian Mitochondrial Ribosome Reveals an Expanded Functional Role for Its Component Proteins. Cell 2003, 115:97-108.

60. Gutell RR, Lee JC, Cannone JJ: The accuracy of ribosomal RNA comparative structure models. Current Opinion in Structural Biology 2002, 12:301-310.

61. Nedelcu A: Fragmented and scrambled mitochondrial ribosomal RNA coding regions among green algae: a model for their origin and evolution. Mol Biol Evol 1997, 14:506-517.

62. Turmel M, Boulanger J, Schnare MN, Gray MW, Lemieux C: Six group introns and three internal transcribed spacers in the chloroplast large 
subunit ribosomal RNA gene of the green alga Chlamydomonas eugametos. J Mol Biol 1991, 218:293-311.

63. Colleaux L, Michel-Wolwertz M-R, Matagne RF, Dujon B: The apocytochrome $b$ gene of Chlamydomonas smithii contains a mobile intron related to both Saccharomyces and Neurospora introns. Mol Gen Genom 1990, 223:288-296.

64. Schnare M, Heinonen T, Young P, Gray M: A discontinuous small subunit ribosomal RNA in Tetrahymena pyriformis mitochondria. J Biol Chem 1986, 261:5187-5193.

65. Burger $G$, Yan Y, Javadi P, Lang BF: Group l-intron trans-splicing and mRNA editing in the mitochondria of placozoan animals. Trends Gen 2009, 25:381-386.

66. Lavrov DV: Key transitions in animal evolution: a mitochondrial DNA perspective. Integr Comp Biol 2007, 47:734-743.

67. Mallatt J, Craig CW, Yoder MJ: Nearly complete rRNA genes assembled from across the metazoan animals: Effects of more taxa, a structurebased alignment, and paired-sites evolutionary models on phylogeny reconstruction. Mol Phyl Evol 2010, 55:1-17.

68. Gissi C, lannelli F, Pesole G: Evolution of the mitochondrial genome of Metazoa as exemplified by comparison of congeneric species. Heredity 2008, 101:301-320

69. Rasmussen S: SEQtools - a program suite for sequence analysis. Book SEQtools - a program suite for sequence analysis (Editor ed.^eds.). City 2002.

70. Holley RW, Apgar J, Everett GA, Madison JT, Merrill SH, Penswick JR, Zamir A: Structure of a ribonucleic acid. Science 1965, 147:1462.

71. Rajbhandary UL, Stuart A, Faulkner RD, Chang SH, Khorana HG: Nucleotide sequence studies on yeast phenylalanine sRNA. Cold Spring Harbor Symposia on Quantitative Biology 1966, 31:425.

72. Madison JT, Everett GA, Kung $\mathrm{H}$ : Nucleotide sequence of a yeast tyrosine transfer RNA. Science 1966, 153:531.

73. Zachau HG, Dutting D, Feldmann H, Melchers F, Karau W: SERINE SPECIFIC TRANSFER RIBONUCLEIC ACIDS .14. COMPARISON OF NUCLEOTIDE SEQUENCES AND SECONDARY STRUCTURE MODELS. Cold Spring Harbor Symposia on Quantitative Biology 1966, 31:417.

74. Levitt M: DETAILED MOLECULAR MODEL FOR TRANSFER RIBONUCLEIC ACID. Nature 1969, 224:759.

75. Kim SH, Suddath FL, Quigley GJ, Sussman JL, Wang AHJ, Seeman NC, Rich A: Three-dimensional tertiary structure of yeast phenylalanine transfer RNA. Science 1974, 185:435-440.

76. Robertus JD, Ladner JE, Finch JT, Rhodes D, Brown RS, Clark BFC, Klug A: Structure of yeast phenylalanine tRNA at $3 \AA$ resolution. Nature 1974, 250:546-551.

77. Fox GE, Woese CR: The architecture of $5 S$ rRNA and its relation to function. J Molec Evol 1975, 6:61-76.

78. Fox GE, Woese CR: 5S RNA secondary structure. Nature 1975, 256:505-507.

79. Woese CR, Magrum LJ, Gupta R, Siegel RB, Stahl DA, Kop J, Crawford N, Brosius R, Gutell R, Hogan JJ, Noller HF: Secondary structure model for bacterial 16S ribosomal RNA: phylogenetic, enzymatic and chemical evidence. Nucl Acids Res 1980, 8:2275-2294.

80. Noller HF, Kop J, Wheaton V, Brosius J, Gutell RR, Kopylov AM, Dohme F, Herr W, Stahl DA, Gupta R, Woese CR: Secondary structure model for $23 \mathrm{~S}$ ribosomal RNA. Nucl Acids Res 1981, 9:6167-6189.

81. Gutell RR, Power A, Hertz GZ, Putz EJ, Stormo GD: Identifying constraints on the higher-order structure of RNA: continued development and application of comparative sequence-analysis methods. Nucl Acids Res 1992, 20:5785-5795.

82. Gautheret D, Damberger SH, Gutell RR: Identification of base-triples in RNA using comparative sequence-analysis. J Mol Biol 1995, 248:27-43.

83. Olsen G: Comparative analysis of nucleotide sequence data. Ph.D. dissertation University of Colorado, Health Sciences Center 1983.

84. Chiu DKY, Kolodziejczak T: Inferring consensus structure from nucleic acid sequences. Computer Applications in the Biosciences 1991, 7:347-352.

85. Gardner PP, Giegerich R: A comprehensive comparison of comparative RNA structure prediction approaches. BMC Bioinformatics 2004, 30:5-140.

86. Krogh A, Brown M, Mian IS, Sjolander K, Haussler D: Hidden Markov Models in Computational Biology - Applications to protein modeling. J Mol Biol 1994, 235:1501-1531.
87. Eddy SR, Mitchison G, Durbin R: Maximum discrimination hidden Markov models of sequence consensus. Journal of Computational Biology 1995, 2:9-23.

doi:10.1186/1471-2164-11-485

Cite this article as: Milbury et al:: Fragmentation of the large subunit ribosomal RNA gene in oyster mitochondrial genomes. BMC Genomics 2010 11:485.

\section{Submit your next manuscript to BioMed Central and take full advantage of:}

- Convenient online submission

- Thorough peer review

- No space constraints or color figure charges

- Immediate publication on acceptance

- Inclusion in PubMed, CAS, Scopus and Google Scholar

- Research which is freely available for redistribution

Submit your manuscript at www.biomedcentral.com/submit
Ciomed Central 